\title{
E-book Culture at Rajshahi University Students in Bangladesh
}

\author{
Purnima Banik*, Md. Armanul Haque, Parveen Sultana, Md. Rayhan Kobir
}

Department of Information Science and Library Management, Rajshahi University, Rajshahi, Bangladesh

Email address:

banik.ru10@gmail.com (P. Banik)

${ }^{*}$ Corresponding author

\section{To cite this article:}

Purnima Banik, Md. Armanul Haque, Parveen Sultana, Md. Rayhan Kobir. E-book Culture at Rajshahi University Students in Bangladesh. International and Public Affairs. Vol. 3, No. 2, 2019, pp. 52-57. doi: 10.11648/j.ipa.20190302.13

Received: June 20, 2019; Accepted: September 28, 2019; Published: October 14, 2019

\begin{abstract}
In the era of Information and Communication Technology, E-books are the blessing for the present world and it has drawn worldwide popularity besides the printed books among the readers. This paper aims at identifying the usage of Ebooks among the science and engineering faculty students at Rajshahi University, Bangladesh. A total of 150 respondents were chosen randomly and distributed with a structured questionnaire where 141 respondents returned the questionnaire. Simple percentage calculations were used to analyze data. The study finds that $100 \%$ of the surveyed students used E-books. Most of students used E-books by Laptop and Smartphone by borrowing from friends and accessing central library databases for improving and gaining knowledge of research and course work in the department. However, most of the students mentioned that they prefer printed books to E-books. Majority of the students agreed that the library should enrich the collections of Ebooks as well as the users and library professionals should be properly trained up Rajshahi University.
\end{abstract}

Keywords: E-books Culture, Digital Devices, Library, Bangladesh

\section{Introduction}

E-books, e-books, eBooks are elaborated as electronic books that are available in the digital platform with text, image, or by both. Computers and other electronic devices are mainly used to read E-books. The advancement of Information and communication technologies have significantly contributed towards the use and access of ebooks by the university students all over the world and universities are, therefore, spending a significant amount of money behind purchasing and subscribing different e-books publishers for their students, researchers and teachers [1]. A variety of works on the use of e-books at academic institutions in developed countries have been done, and most of the students are much aware and access and use e-book for different purposes mostly the educational and research mission [2-5]. Thus, a general awareness about e-book using trends is growing among educated people, and some perceptions are vice versa. However, what is the actual situation of e-books using among users and what are attitudes towards e-books is not transparent to us? From the willingness to know the exact using situation of e-books among users, especially students at the University of Rajshahi in Bangladesh and what they think about e-books was the inspiration to do the research work. The main objective of this study is to find out the exact situation of the usage pattern of e-books and the problems faced by the users while using e-books.

The development of e-book in an institutional setting requires a comprehensive strategy and implementation plan. The purpose of this paper is to measure student's attitudes towards e-books and discover the influencing factors to have relevant results for the future initiatives of using it. The specific objectives of the study are as follows:

(a) to know the purposes of e-book usage;

(b) to identify the users' preference of e-book to printed books;

(c) to find out the problems faced by e-book user while they use an e-book.

(d) to provide some solutions based on the issues. 


\section{Literature Review}

There are many previous studies on the E-book using trends and attitudes in several institutions that are most supportive of the existing research work. Leonard and Snyman [6] conducted a study on the e-book perception among the undergraduate students at the University of Namibia and found that students use and prefer e-books for the course and research purposes. To access and use e-books, they mostly use non-library search engines such as Google, Yahoo and commercial sites. Moreover, the significant impediments that disturbed e-book use were lack of searching skills, slow/unreliable internet and limited or lack of relevant content of e-book collections etc.

Ismail and Awang Ngah [7] described an exploratory study into e-book usage patterns amongst undergraduate students at the Faculty of Computer Science and Information Technology at the University of Malaya, Kuala Lumpur. The study found low usage levels, mainly because students preferred to use printed books and lacked knowledge on how to use e-books. Wu and Chen [8] seen that the attitudes and usages pattern among Taiwanese students were mainly for study and research. The most common types of e-book preferred was monographs, followed by textbooks and reference tools. While asking about the availability of ebooks, they mentioned that university libraries should supply both the electronic and paper versions.

Rafiq and Warraich [9] conducted a study on medical students e-book use in Pakistan, and it was found that the use and non-use of e-books are almost equal among students. Google books were preferred mostly and were used for academic purpose. Besides, users were happy about the upto-datedness, availability, ease of use, access to e-books. Non-users mentioned that different links on the website that provide e-books facilities were ambiguous. Furthermore, they are satisfied with printed books available in their libraries and hesitant to read on screen.

Martindale, Willett and Jones [10] conducted a study on use and perceptions of e-books in Derbyshire Libraries. Their findings were service was very highly valued, and its users would wish it to be continued and, if possible, extended and improved, most obviously by increasing the stock. The principal motivating factors for the use of the service is convenient and time-saving, as opposed to physical remoteness from a library or accessibility. Chennupati K. Ramaiha (2006) explores the user's perceptions of e-books in India. The reader's survey found that Indians are generally willing to use and read e-books though they continue to prefer and use printed publications. Anuradha and Usha (2006) investigated the use and usability of e-books from users' perspectives in an academic and research environment at the Indian Institute of Science. E-Book usage was shallow although students tended to use e-books more than other faculty members and staff.

The work on the use and access to the e-book is limited. The research on e-resources uses been examined by many analysis namely Zabed Ahmed [11], Zabed Ahmed [12], Habiba and Chowdhury [13], Islam and Habiba [14], Siddike and Islam [15]. No research has been undertaken on student use of e-books at the Rajshahi University in Bangladesh. The present study will bear the mark of the issues of strengthening the e-readership among the graduate students of the University of Rajshahi and students of Bangladesh who want to discover e-book for their education and learning.

\section{Data and Methods}

A survey was conducted through questionnaire to collect data on the contemporary e-books using trends and attitudes among Rajshahi University's graduate students. The questionnaire includes only close-ended questions. The questionnaire was prepared based on the objectives of the study and was distributed randomly among the target population.

Rajshahi University, Bangladesh was selected as a research field. More than 32000 students have been studying in nine faculties at 54 departments at this university. So it was not possible to cover all the students as the population. The random selection process was applied to collect data from Science faculty and Engineering faculty. The Engineering faculty consists of six discipline. i.e. Applied Physics and Electronic Engineering (APEE), Applied Chemistry and Chemical Engineering (ACCE), Computer Science and Engineering (CSE), Information and Communication Engineering (ICE), Material Science and Engineering (MSE) and Electrical and Electronic Engineering. Science faculty consists of six disciplines, i.e. Physics, Chemistry, Mathematics, Statistics, Pharmacy and Population Science and Human Resource Development. Populations of the study were nine hundred (900). The study was conducted on one hundred and fifty (150) sample from nine hundred (900) populations. This sample was done randomly. A total of 150 questionnaire were distributed to users with targeted departments. Out of 150 questionnaire, 141 questionnaire were returned, and the same was used for the analysis and results are presented in tabular form.

Table 1. Faculty wise participants.

\begin{tabular}{lll}
\hline Faculty & No. of respondents & Percentage \\
\hline Science & 84 & $59.57 \%$ \\
Engineering & 57 & $40.43 \%$ \\
\hline
\end{tabular}

Table 2. Ratio of participants from various departments.

\begin{tabular}{lll}
\hline Departments & No. of respondents & Percentage \\
\hline Statistics & 21 & $14.89 \%$ \\
Mathematics & 15 & $10.63 \%$ \\
Physics & 11 & $7.80 \%$ \\
Chemistry & 13 & $9.21 \%$ \\
\hline
\end{tabular}




\begin{tabular}{lll}
\hline Departments & No. of respondents & Percentage \\
\hline Applied Mathematics & 9 & $6.38 \%$ \\
Pharmacy. & 12 & $8.51 \%$ \\
Applied Chemistry and Chemical Engineering (ACCE). & 10 & $7.09 \%$ \\
Information and Communication Engineering (ICE). & 15 & $10.63 \%$ \\
Applied Physics and Electronic Engineering (APEE). & 12 & $8.51 \%$ \\
Computer Science and Engineering (CSE). & 14 & 9.92 \\
Population Science and Human Resource Development (PSURD). & 9 & $6.38 \%$ \\
\hline
\end{tabular}

Table 2 shows the department wise respondents. Among 141 respondents $14.89 \%$ Statistics, 10.63\% Mathematics, 7.80\% Physics, 9.21\% Chemistry, 6.38\% Applied mathematics, $8.51 \%$ Pharmacy, $7.09 \%$ ACCE, $10.63 \%$ ICE, 8.51\% APEE, 9.92\% CSE and 6.38\% from PSURD department. There were 141 respondents from 11 various departments.

\section{Results and Discussion}

Collected data were analyzed using percentages and frequency counts.

Table 3. Gender-based participants in the survey.

\begin{tabular}{lll}
\hline Gender & No. respondents & Percentage \\
\hline Male & 108 & $76.60 \%$ \\
Female & 33 & $23.40 \%$ \\
\hline
\end{tabular}

In gender distribution, there were $76.60 \%$ (108 out of 141) male and $23.40 \%$ (33 out of 141) female out of 141 participants.

Table 4. Printed books using trends.

\begin{tabular}{lll}
\hline Frequency of printed books using & $\begin{array}{l}\text { No. of } \\
\text { respondents }\end{array}$ & Percentage \\
\hline Every day & 69 & $48.93 \%$ \\
Some days in a week & 37 & $26.24 \%$ \\
Some days in a month & 24 & $17.02 \%$ \\
Never & 0 & $0 \%$ \\
Rarely & 11 & $7.80 \%$ \\
\hline
\end{tabular}

Table 4 shows printed books using trends among respondents. Out of 141 respondents, $48.93 \%$ answered that they use printed books every day, $26.24 \%$ answered they use printed books someday in a week, $17.02 \%$ answered they use printed books some days in a month, there was no one who never uses printed books, and $7.80 \%$ answered the use of printed books rarely.

Table 5. Sources of using printed books.

\begin{tabular}{lll}
\hline Sources & No. of respondents & Percentage \\
\hline From personal collection & 66 & $46.80 \%$ \\
From the seminar library & 41 & $29.07 \%$ \\
From the central library & 13 & $9.21 \%$ \\
From a teacher & 6 & $4.25 \%$ \\
From the friend & 15 & $10.63 \%$ \\
\hline
\end{tabular}

Table 5 shows the printed books using sources. In response to a question, what sources do you use the printed book, $46 \%$ replayed that they use books from personal collection, $29.07 \%$ from seminar library, 9.21\% from the central library, $4.25 \%$ students replayed they use books from a teacher, and
$10.63 \%$ from their friends.

Table 6. E-books use.

\begin{tabular}{lll}
\hline & No. of respondents & Percentage \\
\hline Yes & 141 & $100 \%$ \\
No & 0 & $0 \%$ \\
\hline
\end{tabular}

Table 6 shows that $100 \%$ of students use e-books besides printed books. No one does not use e-books in the study.

Table 7. E-books using trends.

\begin{tabular}{lll}
\hline Frequency of E-books using & No. of respondents & Percentage \\
\hline Every day & 17 & $12.05 \%$ \\
Some days in a week & 78 & $55.31 \%$ \\
Some days in a month & 33 & $23.40 \%$ \\
Never & 0 & $0 \%$ \\
Rarely & 13 & $9.21 \%$ \\
\hline
\end{tabular}

Out of 141 respondents, $12.05 \%$ answered that they use Ebooks every day, $55.31 \%$ answered they use-books someday in a week, $23.40 \%$ answered they use E-books some days in a month, and $9.21 \%$ answered the use E-books rarely. It is vivid that everybody uses E-books.

Table 8. E-books using frequencies.

\begin{tabular}{lll}
\hline Frequency & $\begin{array}{l}\text { No. of } \\
\text { Respondents }\end{array}$ & Percentage \\
\hline 1 chapter or less & 55 & $39 \%$ \\
1 chapter & 29 & $20.56 \%$ \\
2-3 chapter & 37 & $26.24 \%$ \\
More than 3 chapters but less & 9 & $6.36 \%$ \\
than the whole book & & $7.80 \%$ \\
The entire book & 11 & \\
\hline
\end{tabular}

Table 8 demonstrates that 39\% E-books users read 1 chapter or less, $20.56 \%$ read 1 chapter, $26.24 \%$ read $2-3$ chapters, $6.36 \%$ read more than three chapters, but less than the whole book and $7.80 \%$ read the entire book.

Table 9. E-books using devices.

\begin{tabular}{lll}
\hline Device & No. of respondents & Percentage \\
\hline By printing the book & 9 & $6.38 \%$ \\
In personal computer & 31 & $21.98 \%$ \\
CD-ROM e-book & 3 & 2.12 \\
Smartphone & 47 & $33.33 \%$ \\
Laptop & 51 & $36.17 \%$ \\
\hline
\end{tabular}

In the study, it is seen that $6.38 \%$ users use E-books by printing the book, $21.98 \%$ use E-books in their personal computer, 2.12\% use CD-ROM E-books, 33.33\% use EBook by Smartphone, and highest $36.17 \%$ read E-books by their laptop. 
Table 10. Reasons for using e-books.

\begin{tabular}{lll}
\hline Reasons & No. of respondent & Percentage \\
\hline For research & 15 & $10.63 \%$ \\
For gaining knowledge & 51 & $36.17 \%$ \\
For course work & 42 & $29.78 \%$ \\
For assignment & 33 & $23.40 \%$ \\
\hline
\end{tabular}

As reasons for E-books using 10.63\% users use E-books for research purpose, $36.17 \%$ users use E-books for gaining knowledge, $29.78 \%$ use it for course work, and $23.40 \%$ use it for preparing the assignment.

Table 11. Preference for e-books and printed books.

\begin{tabular}{lll}
\hline Preference option & No. of respondents & Percentage \\
\hline E-book & 36 & $25.53 \%$ \\
Print book & 105 & $74.47 \%$ \\
\hline
\end{tabular}

Table 11 shows the preference of e-books and print books where $25.53 \%$ (36 out of 141) respondents answered they prefer e-book and $74.47 \%$ (105 out of 141) respondents answered that they prefer printed books.

Table 12. Advantages of e-book use.

\begin{tabular}{lll}
\hline Advantages & $\begin{array}{l}\text { No. of } \\
\text { respondents }\end{array}$ & Percentage \\
\hline Available from anywhere & 127 & $22.27 \%$ \\
Full text & 27 & $4.83 \%$ \\
Search capability & 22 & $3.93 \%$ \\
Ability to highlight text & 7 & $1.25 \%$ \\
Ability to make an annotation & 4 & $0.71 \%$ \\
Cut and paste capabilities & 31 & $5.54 \%$ \\
Ability to save to desktop & 22 & $3.93 \%$ \\
Ability to print & 42 & $7.51 \%$ \\
Environment-friendly & 13 & $2.32 \%$ \\
More efficient & 42 & $7.51 \%$ \\
It is portable anywhere & 97 & $17.35 \%$ \\
It saves time instead of going to the library & 55 & $9.83 \%$ \\
It saves me money if I have institutional & 43 & $7.69 \%$ \\
access & 27 & $4.83 \%$ \\
I find pleasure to read an e-book & & \\
\hline
\end{tabular}

There were 14 options of advantages in the questionnaire; respondents choose various options. In total, 559 selected options by respondents within 141 questionnaires. $22.27 \%$ chosen e-books because it is available from anywhere, $4.83 \%$ chosen it because it is available in full text, $3.93 \%$ chosen it because its search capability, $1.25 \%$ chosen because its ability to highlight text, $0.71 \%$ chosen because of its ability to make annotation, $5.54 \%$ chosen because of its cut and paste capabilities, $3.93 \%$ selected because of its ability to save in desktop, $7.51 \%$ chosen it because of its ability to print, $2.32 \%$ chosen it because of its environment friendly, $7.51 \%$ chosen it because of its more efficient, $17.35 \%$ think it is portable anywhere, $9.83 \%$ chosen it because it saves time instead of going to library, $7.69 \%$ selected because of it saves money if I have institutional access, and $4.83 \%$ chosen it because of the find pleasure to read e-book.
Table 13. Access and use of e-books.

\begin{tabular}{lll}
\hline Sources & $\begin{array}{l}\text { No. of } \\
\text { respondents }\end{array}$ & Percentage \\
\hline $\begin{array}{l}\text { Sometimes I buy an e-book from e- } \\
\text { book publishers. }\end{array}$ & 9 & $6.38 \%$ \\
From the publisher's website & 7 & $4.96 \%$ \\
From friend & 36 & $25.53 \%$ \\
From the central library & 32 & $22.69 \%$ \\
I take help from my teacher & 18 & $12.76 \%$ \\
I am literate enough to access and & 39 & $27.65 \%$ \\
download. & & \\
\hline
\end{tabular}

From 141 respondents $6.38 \%$ respondents answered they sometimes buy e-book from e-book publishers, $4.96 \%$ access and use e-books from publisher website, $25.53 \%$ get from the friends, $22.69 \%$ access by central library, $12.76 \%$ access and use e-books by getting help from their teacher and $27.65 \%$ respondents answered they are literate enough to access and download.

Table 14. Satisfaction of users in terms of quality content.

\begin{tabular}{lll}
\hline Satisfaction level & No. of respondents & Percentage \\
\hline Very satisfied & 9 & $6.38 \%$ \\
Satisfied & 72 & $51.06 \%$ \\
Poorly satisfied & 54 & $38.29 \%$ \\
Not satisfied & 6 & $4.25 \%$ \\
\hline
\end{tabular}

In terms of quality content of E-books, 6.38\% users very satisfied with e-books quality, $51.06 \%$ users are satisfied, $38.29 \%$ users are poorly satisfied, and $4.25 \%$ users are not satisfied with e-books quality.

Table 15. Satisfaction of users in terms of subject scope.

\begin{tabular}{lll}
\hline Satisfaction level & No. of respondents & Percentage \\
\hline Very satisfied & 13 & $9.21 \%$ \\
Satisfied & 61 & $43.26 \%$ \\
Poorly satisfied & 52 & $36.87 \%$ \\
Not satisfied & 15 & $10.63 \%$ \\
\hline
\end{tabular}

Table 15 shows that $9.21 \%$ of respondents are very satisfied, $43.26 \%$ of respondents are satisfied, $36.87 \%$ are poorly satisfied, and $10.63 \%$ users are not satisfied with ebooks in terms of subject scope.

Table 16. Satisfaction of user in terms of ease of use.

\begin{tabular}{lll}
\hline Satisfaction level & No. of respondents & Percentage \\
\hline Very satisfied & 7 & $4.96 \%$ \\
Satisfied & 51 & $36.17 \%$ \\
Poorly satisfied & 61 & $43.26 \%$ \\
Not satisfied & 22 & $15.60 \%$ \\
\hline
\end{tabular}

In terms of ease of use, $4.96 \%$ of users are very satisfied, $36.17 \%$ satisfied, $43.26 \%$ are poorly satisfied, and $15.60 \%$ respondents are not satisfied.

Table 17. Users overall satisfaction about e-books.

\begin{tabular}{lll}
\hline Satisfaction level & No. of respondents & Percentage \\
\hline Very satisfied & 7 & $4.96 \%$ \\
Satisfied & 51 & $36.17 \%$ \\
Poorly satisfied & 71 & $50.35 \%$ \\
Not satisfied & 12 & $8.51 \%$ \\
\hline
\end{tabular}


Table 17 demonstrates the overall satisfaction regarding ebooks. $4.96 \%$ of respondents are very satisfied, $36.17 \%$ respondents satisfied, $50.35 \%$ respondents poorly satisfied and $8.51 \%$ not satisfied in terms of overall satisfaction about e-books.

Table 18 showed respondents $34.75 \%$ users think it is very easy to download e-books, $33.33 \%$ users, it is fairly easy to download e-books, $20.56 \%$ think it is quite difficult to

download e-books, and $11.49 \%$ believe it is very difficult to download e-books.

Table 18. Ease or difficulty in downloading e-books.

\begin{tabular}{lll}
\hline Satisfaction level & No. of respondents & Percentage \\
\hline Very easy & 49 & $34.75 \%$ \\
Fairly easy & 47 & $33.33 \%$ \\
Quiet difficult & 29 & $20.56 \%$ \\
Very difficult & 16 & $11.49 \%$ \\
\hline
\end{tabular}

Table 19. Possible benefits after using e-books.

\begin{tabular}{lll}
\hline Benefits after using e-books & No. of respondents & Percentage \\
\hline I gained substantial knowledge of my academic development. & 27 & $19.14 \%$ \\
I gained significant experience in research work. & 26 & $18.43 \%$ \\
It helped to prepare my assignment. & 29 & $20.56 \%$ \\
I gained knowledge of various matters & 22 & $15.60 \%$ \\
It helped to note-taking. & 37 & $26.24 \%$ \\
\hline
\end{tabular}

Among the respondents about possible benefits after using e-books, $19.14 \%$ of respondents gained substantial knowledge on their academic development, $18.43 \%$ of respondents gained significant experience in research work,
$20.56 \%$ got help of e-books to prepare their assignment, $15.60 \%$ gained experience on various matters from e-book and $26.24 \%$ got help of e-books to note-taking.

Table 20. Recommendations on improving the access and usage of e-books.

\begin{tabular}{|c|c|c|}
\hline Recommendations & No. of respondents & Percentage \\
\hline Should increase the subscription with the reputed databases of e-books. & 51 & $13.28 \%$ \\
\hline $\begin{array}{l}\text { Should ensure the smooth, reliable access to the internet by improving the high bandwidth facilities on } \\
\text { the university premises. }\end{array}$ & 47 & $12.23 \%$ \\
\hline Should have highly qualified human resources in the RUCL. & 73 & $19.01 \%$ \\
\hline Should increase the budget of the organization. & 31 & $8.07 \%$ \\
\hline Should ensure available electricity. & 17 & $4.42 \%$ \\
\hline Should arrange the ICT training and workshops in the library & 43 & $11.19 \%$ \\
\hline Should arrange the motivational program in the department to get aware of the students using e-books. & 53 & $13.80 \%$ \\
\hline
\end{tabular}

Table 20 provides some recommendations for using and accessing e-books. $13.78 \%$ recommended to increase the subscription with the reputed databases of e-books, $12.23 \%$ recommended to ensure the smooth, reliable access to the internet by improving the high bandwidth facilities in the university premises, $19.01 \%$ recommended to have highly qualified manpower in the RUCL, $8.07 \%$ recommended to increase the budget of the organization, $4.42 \%$ recommended to ensure available electricity, $11.19 \%$ recommended to arrange the ICT training and workshops in the library, $17.96 \%$ recommended to increase the devices in the seminar library and central library as well and $13.80 \%$ recommended to arrange the motivational program in the department to get aware of the students using e-books.

\section{Major Findings}

The main findings are presented below:

i. The majority $(76.60 \%)$ of the participants were male.

ii. Majority of the students (59.57\%) from Science faculty and lefts $(40.43 \%)$ were from engineering faculty.

iii. A lion share of students (48.93\%) use print books every day, some are some days in a week, and some are some days in a month. iv. $46.80 \%$ of respondents use print books by selfcollection.

v. $100 \%$ of students use e-book besides the printed book.

vi. For the reading e-book, $36.17 \%$ of users use their laptop computer, 33.33\% use their Smartphone.

vii. Among the respondents, $36.17 \%$ of users use e-book for gaining knowledge, $29.78 \%$ use for their course work, $23.40 \%$ used for preparing assignment work and $10.63 \%$ for research.

viii. $74.47 \%$ of respondents prefer print book and $25.53 \%$ prefer e-book.

ix. $22.27 \%$ of respondents think e-book is advantageous because it is available from anywhere, $17 \%$ think it is portable anywhere.

x. $17.96 \%$ of respondents recommend increasing the ICT tools in the central library as well seminar library.

xi. About the overall satisfaction about e-books, 50.35\% of respondents are poorly satisfied, $36.17 \%$ of respondents are satisfied, $8.51 \%$ of respondents are not satisfied, and $4.96 \%$ of respondents are very satisfied.

xii. In terms of ease of downloading, $34.75 \%$ think it is easy to download E-books, $33.75 \%$ think fairly easy, 
$20.56 \%$ think Quiet difficult, and $11.49 \%$ believe it is very difficult.

xiii. In terms of subject scope, $9.21 \%$ of respondents are very satisfied, $43.26 \%$ of respondents are satisfied, $36.87 \%$ are poorly satisfied, and only $10.63 \%$ are not satisfied.

\section{Conclusion and Policy Recommendations}

E-books use mainly for academic development. However, there are some barriers to use E-books such as slow bandwidth, inexpert library staff, and lack of awareness about E-books etc. However, we hope and have a probability of raising E-books usage among the students because technology and technological tools are deeply rooted in the present society and culture.

Based on the findings, the study suggests some policy recommendations are as follows:

i. For improving the use of E-books, students need high-speed internet.

ii. Central library authority can arrange a program to motivate students to study E-books as a focal study point.

iii. The budget of the institution should be increased.

iv. Electro-mania is a cause of not involving with Ebooks, so we have to remove electro-mania by enough tarring.

v. The motivational program in the department to get aware of the students using e-books should be arranged.

vi. There should have highly qualified human resources in the central library as well as a seminar library to provide E-books services.

vii. The subscription with the reputed databases of Ebooks should be increased.

viii. The ICT devices in the seminar library and central library should be increased.

ix. Smooth and reliable access to the internet by improving the high bandwidth facilities on the premises should be ensured.

x. The uninterrupted power supply should cover the whole campus.

\section{References}

[1] SCONUL (2009), Annual Library Statistics, SCONUL, London, available at: www.sconul.ac.uk/statistics/
[2] Nicholas, D., Rowlands, I., Clark, D., Huntington, P., Jamali, H. R. and Ollé, C. (2008). UK scholarly e-book usage: a landmark survey", Aslib Proceedings, 60 (4), 311.

[3] Nicholas, D. and Clark, D. (2012). Reading' in the digital environment. Learned Publishing. 2 (2), 93-98.

[4] Chandra, A., (2013). Why and how can we teach e-Citizens with e-Books?" eCULTURE, 2 (1), 20.

[5] Wilkinson, C., (2015). An investigation into the usage of, and attitudes towards, e-books for academic study among tertiary students in New Zealand. Available at http://researcharchive.

[6] Leonard, A., and Snyman, M., (2019). E-books: yes or no? A case study of undergraduate students at the University of Namibia. Collection and Curation. https://doi.org/10.1108/CC-08-2018-0018.

[7] Ismail, R. and Awang Ngah (2005). The pattern of E-books usage amongst undergraduates in Malaysia: A case of to know is to use. Malaysian Journal of Library and Information Science, 10 (2), 1-23.

[8] Wu, M. D., and Chen, S. C. (2011). Graduate students' usage of and attitudes towards e-books: Experiences from Taiwan. The program, 45 (3), 294-307.

[9] Rafiq, S., and Warraich, N. F., (2018). Medical undergraduate students' perception towards the use and non-use of e-books: a case from Pakistan. Collection and Curation.

[10] Martindale, G., Willett, P., and Jones, R. (2015). Use and perceptions of e-books in Derbyshire libraries. Library review, $64(1 / 2), 2-20$.

[11] Zabed Ahmed, S. M. (2013). Use of electronic resources by the faculty members in diverse public universities in Bangladesh. The Electronic Library, 31 (3), 290-312.

[12] Zabed Ahmed, S. M. (2013). A survey of students' use of and satisfaction with university subscribed online resources in two specialized universities in a developing country. Library $\mathrm{Hi}$ Tech News, 30 (3), 6-8.

[13] Habiba, U., and Chowdhury, S. (2012). Use of electronic resources and its impact: A study of Dhaka University Library users. Eastern Librarian, 23 (1), 74-90.

[14] Islam, M. M., and Habiba, U. (2015). Using Pattern of Internet and E-resources by the Students and Faculty Members of a Private University in Bangladesh. American Journal of Educational Research, 3 (5), 541-546.

[15] Siddike, M. A. K., and Islam, M. S. (2014). Acceptance of eresources by the medical researchers of the International Centre for Diarrhea Disease Research, Bangladesh (ICDDR, B). Journal of Information and Knowledge Management, 13 (02), 1450012. 